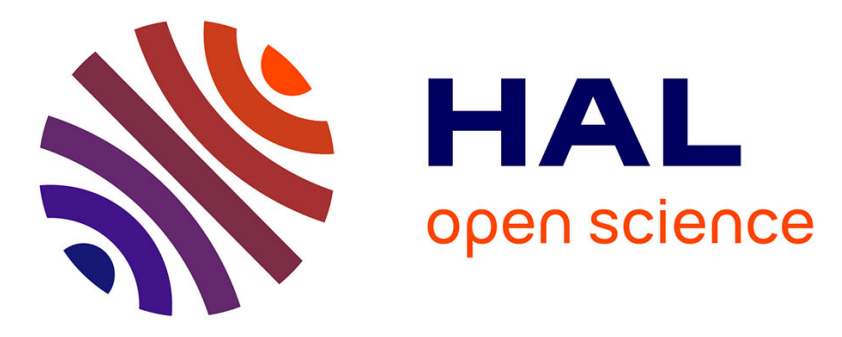

\title{
Relationships between welfare and reproductive performance in French dairy herds
}

Bénédicte Grimard, Alice de Boyer Des Roches, Maud Coignard, Anne

Lehebel, A. Chuiton, Luc Mounier, Isabelle Veissier, Raphaël Guatteo,

Nathalie Bareille

\section{To cite this version:}

Bénédicte Grimard, Alice de Boyer Des Roches, Maud Coignard, Anne Lehebel, A. Chuiton, et al.. Relationships between welfare and reproductive performance in French dairy herds. Veterinary Journal, 2019, 248, pp.1-7. 10.1016/j.tvj1.2019.03.006 . hal-02154586

\author{
HAL Id: hal-02154586 \\ https://hal.science/hal-02154586
}

Submitted on 22 Oct 2021

HAL is a multi-disciplinary open access archive for the deposit and dissemination of scientific research documents, whether they are published or not. The documents may come from teaching and research institutions in France or abroad, or from public or private research centers.
L'archive ouverte pluridisciplinaire HAL, est destinée au dépôt et à la diffusion de documents scientifiques de niveau recherche, publiés ou non, émanant des établissements d'enseignement et de recherche français ou étrangers, des laboratoires publics ou privés.

\section{(ㄷ)(1) $\$$}

Distributed under a Creative Commons Attribution - NonCommerciall 4.0 International 


\section{Original article}

Relationships between welfare and reproductive performance in French dairy herds

B. Grimard ${ }^{\mathrm{a}}$, A. de Boyer des Roches ${ }^{\mathrm{b}}$, M. Coignard ${ }^{\mathrm{c}}$, A. Lehébel ${ }^{\mathrm{c}}$, A. Chuiton $^{\mathrm{a}}$, L. Mounier ${ }^{\mathrm{b}}, \mathrm{I}^{\mathrm{N}}$ Veissier $^{\mathrm{b}}$, R. Guatteo ${ }^{\mathrm{c}}$, N. Bareille ${ }^{\mathrm{c}}$.

a UMR 1198 BDR, INRA, Ecole Nationale Vétérinaire d'Alfort, Université Paris Saclay, Domaine de Vilvert, 78 350, Jouy-en-Josas, France

b UMR 1213 Herbivores, Université Clermont Auvergne, INRA, VetAgroSup, 63122, Saint Gènes Champanelle, France

${ }^{\text {c } U M R} 1300$ BIOEPAR, Oniris, INRA, 44307 Nantes, France

* Corresponding author. Tel.: +33 (0) 143967148.

E-mail address: benedicte.grimard@vet-alfort.fr (B. Grimard). 


\section{Abstract}

This study aimed to investigate the relationship between cow reproductive performance and welfare evaluated at the herd level using the Welfare Quality protocol. The 11 criteria, four principles (good feeding, good housing, good health and appropriate behavior, scale 0 to 100) and overall welfare category (excellent/enhanced/acceptable/not classified=poor welfare) were included as risk factors for calving to first service interval (CFSI) and calving rate (CR). The confounding factors cow breed, parity, season of calving and AI, calving to AI interval, rank of AI (1 to 3) and milk production were taken into account. The sample included 3951 AIs (2172 AI1, 1182 AI2, 597 AI3) in 124 French commercial dairy herds.

Median CFSI was shorter for the cows bred in herds with a higher overall welfare category (median 75 and 76 days in enhanced and acceptable herds vs. 86 in poor welfare ones, $P=0.02$ ). The scores for absence of injuries and expression of social behavior tended to be associated with CFSI $(P<0.10)$. Calving rate $(34.5 \%)$ was not related to the overall welfare category. However, CR was positively related to the good housing score and a positive trend was observed with the score for absence of prolonged hunger and absence of injuries scores. In conclusion, this study confirms a positive relationship between CFSI and welfare in dairy cows with no explicit links with specific aspects of animal welfare.

Keywords: Calving rate; Calving to first service interval; Dairy cow; Fertility; Welfare 


\section{Introduction}

There is currently a serious concern about farm animal welfare in western countries: the vegan and anti-species movements call into question rearing animals. Moreover, consumers want to know how their food is produced. Identifying positive relationships between welfare and productivity might reassure consumers and encourage producers to improve animal welfare in their farms. Moreover, relationships between welfare and routinely recorded data (date of birth, calving date, date of insemination, milk production, milk quality, date of culling...) might help in selecting herds for welfare assessment (Sandgren et al., 2009; de Vries et al., 2014). This has been extensively studied in dairy cows (for a review: (de Vries et al., 2011). For example, in their meta-analysis, Lopez-Gatius et al. (2003) and Bedere et al. (2018) reported significant associations between body condition score (BCS) at calving, BCS change between calving and first service, BCS at nadir and number of days open. Days open were significantly reduced in animals with high BCS at calving showed a significant reduction in days open vs. animals with an intermediate or low BCS. A severe loss ( $>0.5$ points on a 5 point scale) in BCS during early lactation and a low BCS $(\mathrm{BCS} \leq 2)$ at nadir was related to an increase in days open and to a reduction of conception rate compared to a slight $\mathrm{BCS}$ loss and $\mathrm{BCS} \geq 2.5$ at nadir (Chagas et al., 2007; Bedere et al., 2018). However, if days open is a good indicator of the effects of BCS or change in score on reproductive performance, the measurement of conception rate at first service produced variable results among studies. Likewise, lameness (Hernandez et al., 2001; Hernandez et al., 2005) and disease (Fourichon et al., 2000; Raboisson et al., 2014) were clearly related to reproductive performance: affected cows had longer calving to first service interval and required more AIs to become pregnant than healthy cows. The response to the approach of a human was positively associated with conception rate at first service (Hemsworth et al., 2000). However, most studies have focused on only one specific aspect of welfare rather than considering welfare as a whole. 
A protocol allowing the overall assessment of animal welfare at the herd level was developed in Europe in the Welfare Quality project (Botreau et al., 2007; Welfare Quality, 2009; de Vries et al., 2013). This protocol was used in the winter of 2010-2011 in 131 French dairy farms and conducted to identify the main welfare problems and associations between welfare and milk production (Coignard et al., 2013; Coignard et al., 2014; de Boyer des Roches et al., 2014). Coignard et al. (2014) identified positive associations between milk yield and low levels of aggression between cows and good emotional state of the herd. However, milk yield was also associated with low welfare principle scores for Good health assessed by the occurrence of diseases and injuries.

In dairy systems, production performance refers to milk yield and composition but is also related to reproductive performance and longevity. Calving and insemination dates are routinely recorded in most countries. Sangden et al. (2009) and De Vries et al. (2014) have already explored the relationship between reproductive performance and welfare measured at the herd level. However, they did not consider confounding factors in their models. Therefore, the objective of this study was to investigate the relationship between cow reproductive performance and welfare scores measured at the herd level through the Welfare Quality Protocol, in French commercial dairy herds, taking into account confounding factors for reproductive performance recorded in the national database.

\section{Materials and methods}

The study was carried out in 2010 and 2011 using only remote observations; ethical review was not required for this kind of work in 2010 and animal studies were compliant with all applicable provisions established by the European Directive 2010/63/EU. However, 
approval was sought and granted by the VetAgro Sup Ethics Committee for Experiments on Animals (France, agreement number CEEA18) on 5 March, 2019.

\section{Dairy farms and welfare assessment}

This investigation was conducted in the 131 French commercial dairy farms previously studied by de Boyer des Roches et al. (2014). The farms were selected to be representative of the diversity of French dairy systems. They were visited once during the winter, between December 2010 and March 2011.

Animal welfare was estimated using the Welfare Quality (WQ) assessment protocol for dairy cattle (Welfare Quality, 2009). Briefly, 11 welfare criteria were assessed using one to seven measurements (Table 1). Each criterion was evaluated on a scale of 0 (lowest score) to 100 (highest score). These criterion scores were then grouped into four principle welfare scores giving the highest importance to the worst criterion. The four principle scores (good feeding, good housing, good health and appropriate behavior) were also expressed on a scale of 0 (lowest score) to 100 (highest score). Finally, the farm was assigned to an overall welfare category according to their principles scores. Overall welfare was considered to be excellent (at the highest level), if all the scores were $>55$ with two principle welfare scores $>80$, enhanced (good), if the principle welfare scores were all $>20$ with two principle scores $>55$, acceptable (above or meets minimal requirements), if the four principle welfare scores were $>10$ with at least three principle scores $>20$. In the other situations, welfare was considered to be very low and the term used to describe the herd was not classified (poor welfare).

\section{Data recorded and reproductive performance of the cows}


113 National d'Information Génétique): cow breed, dates of calving, parity, milk production during 114 the first 3 months of lactation, insemination dates, breed of the bull used, type of semen (sex sorted or not). Rank 1 to 3 artificial inseminations (AI) performed between the 1 December 2010 to the 31 March 2011 were selected. During this period, cows are housed in France and welfare was considered to be unchanged. In April, most of the cows are put out to grass and this might change their welfare situation. When first service occurred before 20 days postcalving or $>200$ days post-calving, the cows were excluded from the study. When two AIs were separated by an interval shorter than 5 days only the second AI was used and included in the analysis. The use of these inclusion criteria meant that only the data from 124 herds of the 131 were used. The exclusion of the remaining seven herds was due to the fact that an eligible AI was not observed during the period.

Two parameters were calculated to estimate reproductive performance: the calving to first service interval (CFSI) and the calving rate after AI (CR). A cow was considered to be pregnant if its subsequent calving occurred during an interval which was compatible with the average length of pregnancy for the breed \pm 2 standard deviations (SD; as evaluated by Marceau et al. (2014). Cows culled between AI and the end of pregnancy were considered to be non-pregnant as recommended by the International Committed for Animal Recording ${ }^{1}$.

\section{Statistical analysis}

The statistical unit was the AI. The overall welfare category, each principle and each criterion scores were taken into account in the analysis. As previously proposed by Coignard et

\footnotetext{
${ }^{1}$ See: International Committee for Animal Recording, 2016. International Recording Guidelines. https://www.icar.org/index.php/icar-recording-guidelines/ (Accessed 17 March 2019).
} 
al. (2014), the quantitative evaluations of each principle and criterion welfare scores were split into two categories: the first category corresponded to the lowest scores (i.e. scores lower than or equal to the first quartile) observed at cow level and the second category corresponded to the scores above the first quartile. This methodology was chosen to investigate the effects of high welfare impairment rather than to compare the best half to the worst half of herds since in the herds included in this study welfare variability was low (absence of enhanced and low number of poor welfare scored herds).

The relationships between CFSI and the welfare indicators (i.e. overall welfare category, principles and criteria scores) were evaluated using multivariate Cox proportional hazard models. Models were adjusted to take into account the factors likely to influence CFSI: cow breed (Prim'Holstein vs. Montbéliarde and other breeds), parity (primiparous vs. multiparous), season of calving (spring and summer, autumn, winter), mean milk production during the 3 months after calving, season of insemination (autumn vs. winter) and two interactions: parity*milk production and breed*milk production. These factors were selected because they have already been associated with CFSI in the literature (Crowe et al., 2014).

The following model was used:

$h_{i j}\left(t \mid X_{i j}, \alpha_{j}\right)=h_{0}(t) * \exp \left(X_{i j} \beta+\alpha_{j}\right)$

$\alpha_{j} \sim \operatorname{Normal}\left(0, \sigma_{\alpha}^{2}\right)$

where $h_{i j}$ is the hazard function at time t for the probability of AI after a calving for the $i^{t h}$ cows of the $j^{t h}$ herd, $h_{0}(t)$ is the unspecified hazard function, $X_{i j}$ is a matrix containing all adjustment variables previously cited, $\beta$ is the vector of coefficients associated with these variables and $\alpha_{j}$ and $\alpha_{j}$ is a herd random effect. It was assumed to be normally distributed with a mean of 0 and a variance of $\sigma_{\alpha}^{2}$. 

indicators. As previously described, the models were adjusted for factors likely to influence CR

(Walsh et al., 2011) : cow breed, parity, season of calving, mean milk production during the 3 months after calving, season of insemination, rank of AI (1, 2 or 3), interval between calving and AI, type of semen (sex-sorted vs. not sorted) and crossbreeding (bull breed different from the cow breed), parity*milk production and breed*milk production. The model used was:

$Y_{i j} \sim \operatorname{Bernoulli}\left(p_{i j}\right)$

$\ln \left(\frac{p_{i j}}{1-p_{i j}}\right)=X_{i j} \beta+u_{i j}+\alpha_{j}$

$u_{i j} \sim \operatorname{Normal}\left(0, \sigma_{u}^{2}\right)$

$\alpha_{j} \sim \operatorname{Normal}\left(0, \sigma_{\alpha}^{2}\right)$

where the outcome $Y_{i j}$ is the binary variable representing the occurrence of a calving for the cow $i$ in the herd $j, X_{i j}$ is a matrix containing all adjustment variables previously cited, $\beta$ is the vector of coefficients associated with these variables, $u_{i j}$ is the random nested effect for a cow $i$ in a herd $j$ and $\alpha_{j}$ is a herd random effect for the herd $j$. The random effect $u_{i j}$ and $\alpha_{j}$ were assumed to be normally distributed with a mean of 0 and a variance of $\sigma_{u}^{2}$ and $\sigma_{\alpha}^{2}$ respectively.

The quality of the models was estimated using the Akaike Information Criterion (AIC). The model containing the most variables with the lowest AIC was retained. Sixteen Cox proportional hazard models were constructed: for each reproductive performance: one for the overall welfare category, four for each welfare principle scores and 11 for each criteria score. Each welfare score was taken into account alone, and its introduction in the multivariate models aimed to evaluate its effect corrected for the other variation factors susceptible to influence reproductive performance. 
All statistical analyses were performed by using $\mathrm{R}$ software ${ }^{2}$. Cox models were performed using the survival package ${ }^{3}$ (Therneau and Grambsch, 2000) and mixed logistic regression using the lme4 package (Bates et al., 2015). The effect of each welfare score in the different models was evaluated using drop 1 function of stat package and ANOVA function of car package.

\section{Results}

Characteristics of the sample studied

The final data set included 3951 AIs (2172 AI1, 1182 AI2 and 597 AI3) from 2755 cows in 124 herds. The mean number of lactating cows per herd was $51 \pm 17$ (mean \pm SD). A majority of the herds $(52.4 \%)$ were located in lowlands vs. $47.6 \%$ in highlands, $42.0 \%$ used straw bedding vs. $58.0 \%$ cubicles. Milking was performed in a parlor for $83.1 \%$ of the herds and with an automatic system for $16.9 \%$. Cows had access to pasture during the grazing season in $79 \%$ of the herds.

The overall welfare category was enhanced in $38.7 \%(n=48 / 124)$ of the herds, acceptable in $57.3 \%(n=71 / 124)$ and poor welfare in $4.0 \%(5 / 124)$ of them. None of the herds were classed as excellent. The overall welfare category, four principle and 11 criterion-scores recorded in the 124 herds are presented in Table 2. They were described by de Boyer des Roches et al. (2014).

\footnotetext{
${ }^{2}$ See: The R Project for Statistical Computing https://www.r-project.org (Accessed 19 March 2019)

3 See: Therneau T., 2015. A package for survival analysis in R. version 2.38 https://CRAN.Rproject.org/package=survival. (Accessed 21 March 2019)
} 
quartile, the Good feeding score was low mainly due to a low Absence of prolonged thirst score which was attributed when there were too few drinkers ( $>15$ cows by drinking point). The absence of prolonged hunger score was also low in the first quartile, which was related to $>23 \%$ of cows being very thin $(<2.5)$. The good housing score was low when comfort around resting was not adequate. This was related to a long time taken to lie down and to a high percentage of cows which had dirty lower legs. Ease of movement score was high in all the farms because all the cows were loose-housed. The good health score was low in the first quartile mostly related to dehorning practices (disbudding without anesthetic or analgesic), to disease, essentially due to a high percentage of cows with somatic cell counts $>400000$ cells $/ \mathrm{mL}$ and finally to small integument alterations and lameness. The low appropriate behavior score in the first quartile was related to a high number of head butts or other aggressive events per cow per hour (low score for expression of social behaviors), to the low percentage of cows which could be touched or approached within less than $50 \mathrm{~cm}$ (low score for good human-animal relationship) and finally, to negative terms attributed to describe cow behavior (low score for positive emotional state).

The number of cows per herd inseminated during the observation period ranged from one (in one herd) to 56 (in one herd). Most of the cows were bred in the herds classified as enhanced $(n=1145 / 2755 ; 41.6 \%)$ and acceptable $(n=1526 / 2755 ; 55.4 \%)$ welfare. Only $3.0 \%$ ( $n=84 / 2755)$ were bred in the poor welfare herds. The welfare scores observed for the 2755 cows are described in Supplementary material S1. The sample was comprised of mainly Montbéliarde (50.9\%) and Prim'Holstein (45.7\%) cows. Reproductive performance was for the Prim'Holstein, Montbéliarde and other breeds respectively 83, 72, 73 days for the CFSI median and 27.1, 40.9 and $43.2 \%$ for the CR. The result from the 95 cows $(3.4 \%)$ classed as other breeds were grouped with the Montbéliarde cows since their reproductive performance was 
similar. Parity ranged from 1 to 13 . Maximum and mean daily milk production during the first 3 months of lactation were respectively $32.8 \pm 7.8$ and $30.1 \pm 7.3 \mathrm{~kg} / \mathrm{d}$. The main cow characteristics recorded for the cows are presented in Table 3. Crossbreeding was used for $16.4 \%$ of the AIs ( $n=649 / 3951)$ and sex-sorted semen was used for only 75 AI of the 3951 performed.

The median of CFSI was 76 days (mean $81.5 \pm 27.7$ days; $n=2172$ ) and CR was $34.5 \%$ for the whole sample.

\section{Relationship between animal welfare and CFSI}

When introduced in the multivariate model the overall welfare category was significantly related to CFSI $(P=0.02)$. CFSI tended to be associated with the criterion C6 (absence of injuries, $P=0.06$ ) and C9 (expression of social behavior, $P=0.07$; Table 4). For the overall welfare category and C6 (absence of injuries), the higher the welfare category/score the shorter was the CFSI (-11 to -7 days). The relationship was the opposite for C9. CFSI was shorter in the herds where high levels of agonistic interactions were observed between cows (2 days).

related to CFSI. Median CFSI was shorter in Montbéliarde and other breeds compared to Prim'Holstein cows (72.0 vs. 83.0 days; $P<0.001$ ), when calving occurred in autumn compared to spring/summer $(72.0$ vs. 98.0 days; $P<0.0001)$ and when insemination occurred in autumn compared to winter/spring (73.0 vs. 77.0 days; $P<0.0001)$.

\section{Relationship between animal welfare and $C R$}



model because their contribution to model quality was not significant.

259

The overall welfare category was not related to $\mathrm{CR}(P=0.54)$. $\mathrm{CR}$ was significantly related with the P2 criteria (good housing, $P=0.05$; Table 5) and this effect was explained by the relationship between $\mathrm{CR}$ and $\mathrm{C} 3$ (comfort around resting; $P=0.05$ ). Two trends were observed: $\mathrm{CR}$ tended to be related to $\mathrm{C} 1$ (absence of prolonged hunger; $P=0.07$ ) and $\mathrm{C} 6$ (absence of injuries; $P=0.09$ ). For all these associations the higher the score, the higher was the CR (odds ratio 1.21 to 1.24 ).

significantly associated with CR. CR was lower in Prim'Holstein cows than in Montbéliardes and other breeds $(\mathrm{OR}=0.40 ; P<0.0001)$ and was reduced in lower producing $(\leq 26.3 \mathrm{~kg} / \mathrm{d}) v s$ higher producing cows $(>32.8 \mathrm{~kg} / \mathrm{d} ; \mathrm{OR}=0.66 ; P=0.002)$.

\section{Discussion}

This study aimed to assess the relationship between welfare measured at the herd level and reproductive performance in a population selected to reflect the diversity of French dairy farms. We considered potential confounding factors of our two indicators of reproductive performance: calving to first service interval (CFSI) and calving rate (CR). In most of our herds, cows go to pasture for the grazing period. This is likely to affect their welfare: access to food and water, comfort around resting, cleanliness, integument alterations, lameness, diseases, somatic cell count, expression of social behavior might be modified when grazing. We therefore limited our observations to the indoor period. This reduced the size of our dataset. However, 
the number of inseminations selected was high enough to investigate relationships between welfare and reproduction performance considering known confounding factors.

The herds included in our sample were slightly larger in size than the average French herd (51 vs. 41 dairy cows, (Agreste, 2016)). We included mainly Prim'Holstein and Montbéliarde cows in our study which are the main two French dairy breeds (66 and 17\% of the French population, (France Génétique Elevage, 2016).

The reproductive performance of the cows enrolled in this study were close to that observed for the French cow population (Le Mezec, 2017). Mean CFSI was slightly shorter than that observed in the French cow population (98 days for Prim'Holstein and 80 for Montbéliarde cows, (Le Mezec, 2017)). The high proportion of Montbéliarde cows in our sample reduced the mean CFSI observed. Moreover, we excluded CFSIs over to 200 days from our analysis. CR was slightly lower than that observed in the French population $37.1 \%$ in Prim'Holstein cows and 49.2\% in Montbéliarde ones, (Le Mezec, 2017)). However, Le Mezec calculated the calving rate without taking into account culled cows. Moreover, they included only parity from 1 to 3 . In our analysis, all the culled cows were considered to be not pregnant and we included all ranks of lactation (range from 1 to 13). This might have reduced our estimation of CR (Walsh et al., 2011).

In our study, none of the herds were classified as excellent after welfare was evaluated and only five herds were not classified (poor welfare, considered to be unacceptable). The absence of excellent herds has already been observed by de Vries et al. (2013) in a sample of 196 herds in The Netherlands even though they were selected to have a wide range of levels of animal welfare. This could mean that the level of dairy herd welfare is low in Europe or that 
the system of evaluation is not adapted to current dairy cow rearing practices. The low number of poor welfare farms might be explained by the fact that herd recruitment was voluntary in our study. Consequently, the relatively low variability in the welfare score in our sample might have reduced the statistical power of our investigation.

The calving to first service interval was related to the overall welfare category calculated with the Welfare Quality Protocol: the median CFSI was reduced by 11 days in the herds with the best score (enhanced and acceptable in our study) compared to the worst (poor welfare). This is in favor of a positive relationship between welfare and productivity.

However, CFSI was not significantly associated with the principle or criterion scores were significantly associated to CFSI. Two welfare criteria tented to be associated with CFSI: Absence of injuries and expression of social behavior. The higher the score for Absence of injuries, the shorter was the median CFSI. Lameness is taken into account in this criterion and a negative relationship with CFSI has already been observed by Fourichon et al. (2000) in their meta-analysis and by Hernandez et al. (2001) in 837 Holstein cows. For Hernandez et al. (2005), calving to conception interval was increased in lame cows which may be related to an effect on CFSI but also on conception rate. Moreover, Sandgren et al. (2009), explored the potential of using information recorded in the national database for use as indicators of animal welfare and they identified a relationship between calving interval with a score for injuries and inflammation and animal cleanliness (the better the score the shorter was the calving interval). This is in agreement with our observation.

Herds with a high frequency of agonistic interactions (taken into account in C9, expression of social behavior) tended to have a shorter CFSI. We can hypothesise that, the 
shorter the CFSI, the higher was the probability to observe cows in heat in the herd. Indeed, agonistic interactions between cows are observed when they are in oestrus (Orihuela, 2000; Kerbrat and Disenhaus, 2004; Roelofs et al., 2010).

Surprisingly, the criterion absence of prolonged hunger estimated by the proportion of very thin cows, was not related to CFSI even though low body condition score at calving and high BCS loss after calving are known to increase the length of postpartum anœstrus in dairy cows (Chagas et al., 2007; Crowe et al., 2014; Bedere et al., 2018). This might be related to the methodology used to estimate this criterion in the Welfare Quality protocol. BCS was evaluated on a sample of lactating and dry cows and pregnant heifers. A very lean cow corresponding to a BCS $<2$. The criterion was noted at a herd level and the score is lower than 20 (as in our first quartile) if between $20 \%$ to $100 \%$ of cows are very lean. In high producing dairy herds, a physiological loss of BCS is observed after calving. A proportion of $20 \%$ of thin cows is perhaps not detrimental enough to affect CFSI if only observed in early lactating cows. It might be of interest to differentiate between two criteria in the Welfare Quality Protocol: very low BCS observed in dry cows, pregnant heifers, late lactating vs. early lactating cows. Therefore, it seems that an improvement in animal welfare is likely to reduce the interval between calving and insemination even though no specific aspect of animal welfare seems to have a prominent effect.

In our study, CR rate was not related to the overall welfare category. However, a significant relationship was observed between the principle good housing, the criterion comfort around resting and CR. In our study, this was not related to the type of housing (cubicles vs. straw bedding, data not shown). To our knowledge, the link between cow comfort and CR has not been previously documented. The score for comfort around resting was the main factor 
which influence the good housing score in our study. The other parameter taken into account to calculate the P2 principle (good housing) is ease of movement which was high in all our herds because all the cows were reared in loose housing systems. CR also tended to be associated with absence of prolonged hunger and absence of injuries which is in agreement with previous observations: low body condition score, lameness and claw disorders have been shown to be related to low conception rate (Fourichon et al., 2000; Hernandez et al., 2001; LopezGatius et al., 2003; Hernandez et al., 2005; Bedere et al., 2018). All the association or trends observed were positive: CR was higher when welfare scores were high. However, CR seemed only to be related to certain specific aspect of welfare aspect (comfort around resting) and this needs further investigations to be understand.

Finally, CFSI was more closely related to animal welfare measured at herd level than CR. Therefore, the CFSI seems therefore to be more relevant when selecting herds before conducting visits for on farm welfare assessment.

The other risk factors for poor reproductive performance identified in this work have often been observed in other studies. CFSI was related to cow breed, season of calving and season of AI as observed for French cattle in general (Le Mezec, 2017). CR was related to cow breed and milk yield. The breed effect observed in this study has already been described in the French and in the European cattle populations (European Food Safety Authority, 2009; Le Mezec, 2017). The positive association between milk yield and CR (increase of CR with the increase in milk yield) is not consistent with the generally accepted idea that there is a negative relationship between milk yield and reproductive performance. However, some authors have highlighted potential bias in this association (LeBlanc, 2010). In our study, the lower category of milk production during the three first months of lactation was very low ( $\leq 26.3 \mathrm{~kg} / \mathrm{d})$. Animals 
which produce less than this might have an alteration in health or a nutritional deficiency if the diet is insufficient/unbalanced.

\section{Conclusions}

We identified positive associations between good welfare and reproductive performance. CFSI was shorter for the cows bred in herds with enhanced and acceptable overall welfare category and a trend was observed for the association with absence of injuries. CR was not related to overall welfare category but was significantly higher in the farms with a high comfort around resting score. Our study suggests that CFSI might be reduced by better animal welfare. This result is likely to encourage dairy producers to improve welfare on their farms. Moreover, a long CFSI which is routinely recorded, could be used as a criterion to help in the identification of herds where it would be appropriate look more closely at animal welfare.

\section{Conflict of interest statement}

This work was supported by Danone Research. None of the authors has any other financial or personal relationships that could inappropriately influence or bias the content of the paper.

\section{Acknowledgements}

The authors thank François Beaudeau (Oniris) for his useful advice on statistical analysis and Andrew Ponter for checking the English language of the manuscript. This work received financial support from Danone Research and pole ESTIVE. We thank the Groupements de Défense Sanitaire (GDS) for providing lists of eligible farms, France Génétique Elevage for access to data and all the farmers who co-operated in this survey. We are also particularly grateful to Eric Delval (INRA), Christophe Mallet (INRA) and Remi 
Debauchez (ISARA) for their help in data collection, Jean-Yves Audiart (ONIRIS) and Didier Billon (ONIRIS) for their help in data entry, Anne Lamadon (INRA), Yoan Gaudron (INRA) and Pascal Champciaux (INRA) for calculating the welfare scores.

\section{Appendix: Supplementary material}

Supplementary data associated with this article can be found in the online version at doi:...

\section{References}

Agreste, 2016. Produits agroalimentaires : Bovins, In: Graphagri. Ministère de l'Agriculture et de l'Alimentation, Paris, France, pp. 150-152.

Bates, D., Maechler, M., Bolker, B., Walker, S., 2015. Fitting Linear Mixed-Effects Models Using lme4. Journal of Statistical Software 67, 1-48.

Bedere, N., Cutillic, E., Delaby, L., Garcia-Launay, F., Disenhaus, C., 2018. Meta-analysis of the relationships between reproduction, milk yield and body condition score in dairy cows. Livestock Sience 210, 73-84.

Botreau, R., Veissier, I., Butterworth, A., Brake, M.B.M., L.J., K., 2007. Definition of criteria for overall assessment of animal welfare. Animal Welfare, 225-228.

Chagas, L.M., Bass, J.J., Blache, D., Burke, C.R., Kay, J.K., Lindsay, D.R., Lucy, M.C., Martin, G.B., Meier, S., Rhodes, F.M., Roche, J.R., Thatcher, W.W., Webb, R., 2007. Invited review: New perspectives on the roles of nutrition and metabolic priorities in the subfertility of high-producing dairy cows. Journal of Dairy Science 90, 4022-4032.

Coignard, M., Guatteo, R., Veissier, I., de Boyer des Roches, A., Mounier, L., Lehebel, A., Bareille, N., 2013. Description and factors of variation of the overall health score in French dairy cattle herds using the Welfare Quality assessment protocol. Preventive Veterinary Medicine 112, 296-308.

Coignard, M., Guatteo, R., Veissier, I., Lehebel, A., Hoogveld, C., Mounier, L., Bareille, N., 2014. Does milk yield reflect the level of welfare in dairy herds? Veterinary Journal 199, 184-187.

Crowe, M.A., Diskin, M.G., Williams, E.J., 2014. Parturition to resumption of ovarian cyclicity: comparative aspects of beef and dairy cows. Animal 8 Suppl 1, 40-53.

de Boyer des Roches, A., Veissier, I., Coignard, M., Guatteo, R., Capdeville, J., GilotFromont, E., Mounier, L., 2014. The major welfare problems of dairy cows in French commercial farms: an epidemiological approach. Animal Welfare 23, 467-478. 
de Vries, M., Bokkers, E.A., Dijkstra, T., van Schaik, G., de Boer, I.J., 2011. Invited review: Associations between variables of routine herd data and dairy cattle welfare indicators. Journal of Dairy Science 94, 3213-3228.

de Vries, M., Bokkers, E.A., van Schaik, G., Botreau, R., Engel, B., Dijkstra, T., de Boer, I.J., 2013. Evaluating results of the Welfare Quality multi-criteria evaluation model for classification of dairy cattle welfare at the herd level. Journal of Dairy Science 96, 6264-6273.

de Vries, M., Bokkers, E.A., van Schaik, G., Engel, B., Dijkstra, T., de Boer, I.J., 2014. Exploring the value of routinely collected herd data for estimating dairy cattle welfare. Journal of Dairy Science 97, 715-730.

European Food Safety Authority, 2009. Scientific report of EFSA prepared by the Animal Health and Animal Welfare Unit on the effect of farming systems on dairy cow welfare and disease. Annex to the EFSA Journal 1143, 8-284.

Fourichon, C., Seegers, H., Malher, X., 2000. Effect of disease on reproduction in the dairy cow: a meta-analysis. Theriogenology 53, 1729-1759.

France Génétique Elevage, 2016. Dispositif Génétique : Chiffres Clés des Ruminats 2015. France Génétique Elevage, Paris, France.

Hemsworth, P.H., Coleman, G.J., Barnett, J.L., Borg, S., 2000. Relationships between humananimal interactions and productivity of commercial dairy cows. Journal of Animal Science 78, 2821-2831.

Hernandez, J., Shearer, J.K., Webb, D.W., 2001. Effect of lameness on the calving-toconception interval in dairy cows. Journal of the American Veterinary Medical Association 218, 1611-1614.

Hernandez, J.A., Garbarino, E.J., Shearer, J.K., Risco, C.A., Thatcher, W.W., 2005. Comparison of the calving-to-conception interval in dairy cows with different degrees of lameness during the prebreeding postpartum period. Journal of the American Veterinary Medical Association 227, 1284-1291.

Kerbrat, S., Disenhaus, C., 2004. A proposition for an updated behavioural characterisation of the oestrus period in dairy cows. Applied Animal Behaviour Science 87, 223-238.

Le Mezec, P., 2017. Fertilité des principales races laitières. Bilan 1999-2015. Institut de l'Elevage, Paris, France.

LeBlanc, S., 2010. Assessing the association of the level of milk production with reproductive performance in dairy cattle. The Journal of Reproduction and Development 56 Suppl, S1-7.

Lopez-Gatius, F., Yaniz, J., Madriles-Helm, D., 2003. Effects of body condition score and score change on the reproductive performance of dairy cows: a meta-analysis. Theriogenology 59, 801-812.

Marceau, A., Madouasse, A., Lehebel, A., van Schaik, G., Veldhuis, A., Van der Stede, Y., Fourichon, C., 2014. Can routinely recorded reproductive events be used as indicators 
of disease emergence in dairy cattle? An evaluation of 5 indicators during the emergence of bluetongue virus in France in 2007 and 2008. Journal of Dairy Science 97, 6135-6150.

Orihuela, A., 2000. Some factors affecting the behavioural manifestation of oestrus in cattle: a review. Applied Animal Behaviour Science 70, 1-16.

Raboisson, D., Mounie, M., Maigne, E., 2014. Diseases, reproductive performance, and changes in milk production associated with subclinical ketosis in dairy cows: a metaanalysis and review. Journal of Dairy Science 97, 7547-7563.

Roelofs, J., Lopez-Gatius, F., Hunter, R.H., van Eerdenburg, F.J., Hanzen, C., 2010. When is a cow in estrus? Clinical and practical aspects. Theriogenology 74, 327-344.

Sandgren, C.H., Lindberg, A., Keeling, L.J., 2009. Using a national dairy database to identify herds with poor welfare. Animal Welfare, 523-532.

Therneau, T., Grambsch, P., 2000. Modeling Survival Data: Extending the Cox Model. Springer, New York, USA.

Walsh, S.W., Williams, E.J., Evans, A.C., 2011. A review of the causes of poor fertility in high milk producing dairy cows. Animal Reproduction Science 123, 127-138.

Welfare Quality, 2009. Welfare Quality Assassment protocols: Cattle protocol without veal calves. Welfare Quality Consortium, Lelystad, The Netherlands. 
502 The Welfare Quality protocol in dairy cattle: observations used to estimate the four principles

503 (P) and the 12 criteria $(\mathrm{C})$ welfare scores.

Principle and Criteria $\quad$ Measure

P1: Good Feeding

$\mathrm{C} 1$ : Absence of prolonged hunger

C2: Absence of prolonged thirst

P2: Good Housing

C3: Comfort around resting

C4: Thermal comfort

C5: Ease of movement

P3: Good Health

C6: Absence of injuries

C7: Absence of disease

C8: Absence of pain induced by management procedures

P4: Appropriate behavior
Body condition score

Provision of water

Behavior at lying

Cleanliness of cows

No measure available

Possibility for cows to walk

Clinical observations: Lameness

Clinical observation: Integument alterations

Clinical observations (coughing, nasal discharge, dyspnoea, vulval discharge...)

Farm records: Milk somatic cell count over the 3 last months; dystocia; downer cow; mortality over the last 12 months

Dehorning practices 
C9: Expression of social behaviors

C10: Expression of other behaviors

C11: Good Human-Animal

relationship

C12: Positive emotional state
Interaction between cows (aggressive events per cow per h)

Access to pasture

Avoidance distance of cow when approached at the feeding rack

Qualitative behavior assessment

505

506 
508 Welfare scores ${ }^{\text {a }}$ recorded in 124 herds according to the Welfare Quality protocol assessment 509

\begin{tabular}{|c|c|c|c|c|c|}
\hline Variable & Minimum & $\begin{array}{c}\text { First } \\
\text { quartile }\end{array}$ & Median & $\begin{array}{c}\text { Third } \\
\text { quartile }\end{array}$ & Maximum \\
\hline Good feeding (P1) & 3.5 & 14.6 & 43.5 & 64.8 & 100.0 \\
\hline Absence of prolonged hunger $(\mathrm{C} 1)$ & 2.5 & 27.9 & 49.3 & 100.0 & 100.0 \\
\hline Absence of prolonged thirst $(\mathrm{C} 2)$ & 3.0 & 3.0 & 60.0 & 100.0 & 100.0 \\
\hline Good housing (P2) & 35.2 & 51.6 & 59.4 & 66.2 & 79.8 \\
\hline Comfort around resting (C3) & 0.0 & 26.1 & 38.6 & 49.2 & 70.9 \\
\hline Ease of movement (C5) & 95.0 & 95.0 & 95.0 & 95.0 & 95.0 \\
\hline Good health (P3) & 13.4 & 25.5 & 29.5 & 35.8 & 52.4 \\
\hline Absence of injuries (C6) & 8.7 & 39.1 & 55.7 & 69.2 & 100.0 \\
\hline Absence of disease (C7) & 11.9 & 26.6 & 33.4 & 44.9 & 86.1 \\
\hline Absence of pain induced by & 2.0 & 20.0 & 20.0 & 28.0 & 100.0 \\
\hline \multicolumn{6}{|l|}{ management procedures $(\mathrm{C} 8)$} \\
\hline Appropriate behavior $(\mathrm{P} 4)$ & 6.5 & 26.6 & 37.4 & 44.7 & 69.0 \\
\hline Expression of social behaviors (C9) & 0.0 & 20.5 & 41.3 & 61.7 & 95.8 \\
\hline Expression of other behaviors $(\mathrm{C} 10)$ & 0.0 & 77.2 & 82.3 & 86.5 & 100.0 \\
\hline Good human-animal relationship (C11) & 13.7 & 33.5 & 41.6 & 51.0 & 69.6 \\
\hline Positive emotional state (C12) & 1.3 & 34.9 & 49.0 & 66.5 & 93.3 \\
\hline
\end{tabular}


513 Characteristics of the 2,755 dairy cows included in the study.

514

\begin{tabular}{|c|c|c|}
\hline Variable & $n$ & Percentage \\
\hline \multicolumn{3}{|l|}{ Overall welfare category of the herd } \\
\hline Enhanced & 1145 & 41.6 \\
\hline Acceptable & 1526 & 55.4 \\
\hline Poor welfare & 84 & 3.0 \\
\hline \multicolumn{3}{|l|}{ Cow breed } \\
\hline Prim'Holstein & 1258 & 45.7 \\
\hline Montbeliarde and others ${ }^{\mathrm{a}}$ & 1497 & 54.3 \\
\hline \multicolumn{3}{|l|}{ Parity } \\
\hline Primiparous & 974 & 35.4 \\
\hline Multiparous & 1781 & 64.6 \\
\hline \multicolumn{3}{|l|}{ Month of calving } \\
\hline Spring and Summer (April to September) & 995 & 36.1 \\
\hline Autumn (October to December) & 1579 & 57.3 \\
\hline Winter (January to March) & 181 & 6.6 \\
\hline \multicolumn{3}{|c|}{$\begin{array}{l}\text { Highest daily milk production during the first } 3 \text { months } \\
(\mathrm{kg} / \mathrm{d})\end{array}$} \\
\hline$\leq 28.6$ & 910 & 33.0 \\
\hline$(28.6 ; 35.6)$ & 927 & 33.6 \\
\hline$>35.6$ & 918 & 33.3 \\
\hline \multicolumn{3}{|c|}{$\begin{array}{l}\text { Mean daily milk production during the first } 3 \text { months } \\
(\mathrm{kg} / \mathrm{d})\end{array}$} \\
\hline$\leq 26.3$ & 908 & 33.0 \\
\hline$(26.3 ; 32.8)$ & 927 & 33.6 \\
\hline$>32.8$ & 920 & 33.4 \\
\hline
\end{tabular}

a 95 cows of other breeds 
518 Associations between overall welfare category, principles and criteria scores (measured at herd

519 level) and calving to first service interval (CFSI) in 124 French dairy herds $(n=2172$ AI1). The

520 scores were introduced one by one in a multivariate model taking into account breed, parity,

521 season of calving, season of AI, milk production and interactions between milk 522 production*breed and milk production*parity.

\begin{tabular}{|c|c|c|c|c|c|c|}
\hline & & & CFSI & & & \\
\hline & Score & $n$ & median & HR & $95 \% \mathrm{CI}$ & $P$ \\
\hline \multirow[t]{3}{*}{ Overall welfare category } & Acceptable & 1202 & 76 & Ref & - & \multirow{3}{*}{0.02} \\
\hline & Enhanced & 907 & 75 & 0.93 & $0.78-1.12$ & \\
\hline & Poor welfare & 63 & 86 & 0.68 & $0.86-1.06$ & \\
\hline \multirow[t]{2}{*}{ Good feeding (P1) } & $\leq 14.6$ & 573 & 75 & Ref. & - & \multirow{2}{*}{0.65} \\
\hline & $>14.6$ & 1599 & 76 & 1.05 & $0.86-1.28$ & \\
\hline \multirow[t]{2}{*}{ Good housing (P2) } & $\leq 52.0$ & 601 & 79 & Ref. & - & \multirow{2}{*}{0.26} \\
\hline & $>52.0$ & 1571 & 74 & 1.12 & $0.92-1.35$ & \\
\hline \multirow[t]{2}{*}{ Good Health (P3) } & $\leq 25.5$ & 561 & 80 & Ref. & - & \multirow{2}{*}{0.14} \\
\hline & $>25.5$ & 1611 & 75 & 1.16 & $0.95-1.41$ & \\
\hline Appropriate behavior & $\leq 26.7$ & 576 & 77 & Ref. & - & \multirow{2}{*}{0.67} \\
\hline$(\mathrm{P} 4)$ & $>26.7$ & 1596 & 76 & 0.96 & $0.79-1.17$ & \\
\hline Absence of prolonged & $\leq 28.9$ & 552 & 82 & Ref. & - & \multirow{2}{*}{0.19} \\
\hline hunger $(\mathrm{C} 1)$ & $>28.9$ & 1620 & 74 & 1.15 & $0.94-1.40$ & \\
\hline Absence of prolonged & $\leq 3.0$ & 573 & 75 & Ref. & - & \multirow{2}{*}{0.65} \\
\hline thirst $(\mathrm{C} 2)$ & $>3.0$ & 1599 & 76 & 1.05 & $0.86-1.28$ & \\
\hline Comfort around resting & $\leq 26.8$ & 601 & 79 & Ref. & - & \multirow{2}{*}{0.26} \\
\hline (C3) & $>26.8$ & 1571 & 74 & 1.12 & $0.92-1.35$ & \\
\hline
\end{tabular}




\begin{tabular}{|c|c|c|c|c|c|c|}
\hline Absence of injuries & $\leq 40.6$ & 559 & 81 & Ref. & - & \multirow{2}{*}{0.06} \\
\hline (C6) & $>40.6$ & 1613 & 74 & 1.20 & $0.99-1.45$ & \\
\hline \multirow[t]{2}{*}{ Absence of disease (C7) } & $\leq 24.6$ & 541 & 78 & Ref. & - & \multirow{2}{*}{0.37} \\
\hline & $>24.6$ & 1631 & 75 & 1.10 & $0.90-1.34$ & \\
\hline Absence of pain induced & $\leq 20.0$ & 1362 & 76 & Ref. & - & \multirow[b]{2}{*}{0.54} \\
\hline $\begin{array}{l}\text { by management } \\
\text { procedures }(\mathrm{C} 8)\end{array}$ & $>20.0$ & 810 & 76 & 0.95 & $0.79-1.13$ & \\
\hline Expression of social & $\leq 23.9$ & 580 & 74 & Ref. & - & \multirow{2}{*}{0.07} \\
\hline behaviors (C9) & $>23.9$ & 1592 & 76 & 0.84 & $0.69-1.01$ & \\
\hline Expression of other & $\leq 77.2$ & 593 & 76 & Ref. & - & \multirow{2}{*}{0.99} \\
\hline behaviors (C10) & $>77.2$ & 1579 & 76 & 1.00 & $0.82-1.22$ & \\
\hline Good human-animal & $\leq 34.1$ & 549 & 77 & Ref. & - & \multirow{2}{*}{0.63} \\
\hline relationship (C11) & $>34.1$ & 1623 & 76 & 0.95 & $0.79-1.16$ & \\
\hline Positive emotional state & $\leq 34.1$ & 557 & 75 & Ref. & - & \multirow{2}{*}{0.53} \\
\hline (C12) & $>34.1$ & 1615 & 76 & 1.07 & $0.87-1.30$ & \\
\hline
\end{tabular}

523 HR, Hazard ratio; CI, Confidence Interval; Ref., Reference category 
525 Table 5

526 Associations between overall welfare category, principles and criteria scores (measured at herd 527 level) and calving rate (CR) in 124 French dairy herds $(n=3,951$; rank 1 - 3 artificial 528 insemination $[\mathrm{AI}]$ in 2,755 dairy cows). The scores were introduced one by one in a multivariate 529 model taking into account breed, parity, season of calving, season of AI, rank of AI, milk 530 production and interactions between milk production*breed and milk production*parity.

\begin{tabular}{|c|c|c|c|c|c|}
\hline & & $n$ & OR & $95 \% \mathrm{CI}$ & $P$ \\
\hline \multirow[t]{3}{*}{ Overall welfare category } & Acceptable & 2182 & Ref. & - & \multirow{3}{*}{0.54} \\
\hline & Enhanced & 1647 & 1.12 & {$[0.91 ; 1.37)$} & \\
\hline & Poor welfare & 122 & 1.12 & {$[0.66 ; 1.91)$} & \\
\hline \multirow[t]{2}{*}{ Good feeding (P1) } & $\leq 14.6$ & 1031 & Ref. & - & \multirow{2}{*}{0.62} \\
\hline & $>14.6$ & 2920 & 1.06 & {$[0.85 ; 1.32)$} & \\
\hline \multirow[t]{2}{*}{ Good housing (P2) } & $\leq 52.0$ & 1084 & Ref. & - & \multirow{2}{*}{0.05} \\
\hline & $>52.0$ & 2867 & 1.24 & {$[1.00 ; 1.55)$} & \\
\hline \multirow[t]{2}{*}{ Good Health (P3) } & $\leq 25.5$ & 1010 & Ref. & - & \multirow{2}{*}{0.46} \\
\hline & $>25.5$ & 2941 & 1.09 & {$[0.87 ; 1.38)$} & \\
\hline \multirow[t]{2}{*}{ Appropriate behavior (P4) } & $\leq 26.7$ & 1047 & Ref. & - & \multirow{2}{*}{0.43} \\
\hline & $>26.7$ & 2904 & 1.09 & {$[0.88 ; 1.37)$} & \\
\hline Absence of prolonged hunger & $\leq 28.9$ & 1061 & Ref. & - & \multirow{2}{*}{0.07} \\
\hline (C1) & $>28.9$ & 2890 & 1.24 & {$[0.98 ; 1.57)$} & \\
\hline Absence of prolonged thirst & $\leq 3.0$ & 1031 & Ref. & - & \multirow{2}{*}{0.62} \\
\hline$(\mathrm{C} 2)$ & $>3.0$ & 2920 & 1.06 & {$[0.85 ; 1.32)$} & \\
\hline \multirow[t]{2}{*}{ Comfort around resting (C3) } & $\leq 26.8$ & 1084 & Ref. & - & \multirow{2}{*}{0.05} \\
\hline & $>26.8$ & 2867 & 1.24 & {$[1.00 ; 1.55)$} & \\
\hline Absence of injuries (C6) & $\leq 40.6$ & 1017 & Ref. & - & 0.09 \\
\hline
\end{tabular}




$\begin{array}{lrccc}>40.6 & 2934 & 1.21 & {[0.97 ; 1.52)} & \\ \leq 24.6 & 996 & \text { Ref. } & - & 0.46 \\ >24.6 & 2955 & 1.09 & {[0.86 ; 1.38)} & \\ \leq 20.0 & 2516 & \text { Ref. } & - & 0.38 \\ >20.0 & 1435 & 1.09 & {[0.89 ; 1.34)} & \\ \leq 23.9 & 995 & \text { Ref. } & - & 0.98 \\ >23.9 & 2956 & 1.00 & {[0.80 ; 1.25)} & \\ \leq 77.2 & 1102 & \text { Ref. } & - & 0.83 \\ >77.2 & 2849 & 0.98 & {[0.78 ; 1.22)} & \\ \leq 34.1 & 1006 & \text { Ref. } & - & \\ >34.1 & 2945 & 0.93 & {[0.75 ; 1.16)} & \\ \leq 34.1 & 976 & \text { Ref. } & - & 0.53 \\ >34.1 & 2975 & 1.00 & {[0.80 ; 1.25)} & \end{array}$

Absence of disease (C7)

Absence of pain induced by

management procedures $(\mathrm{C} 8)$

Expression of social behaviors

Expression of other behaviors

Good human-animal

relationship (C11)

Positive emotional state (C12)

$>34$

$$
\text { OR, Odds Ratio; CI, Confidence Interval; Ref., Reference category }
$$

